\title{
Comparison of silver, cesium, and strontium release predictions using PARFUME with results from the AGR-1 irradiation experiment
}

\author{
Blaise P. Collin, David A. Petti, Paul A. Demkowicz, John T. Maki \\ Idaho National Laboratory \\ 2525 Fremont Avenue, Idaho Falls, ID 83415, USA \\ Phone:+1-208-526-2217, blaise.collin@inl.gov
}

\begin{abstract}
The PARFUME (PARticle FUel ModEl) code was used to predict the release of fission products silver, cesium, and strontium from tristructural isotropic coated fuel particles and compacts during the first irradiation experiment (AGR-1) of the Advanced Gas Reactor Fuel Development and Qualification program. The PARFUME model for the AGR-1 experiment used the fuel compact volume average temperature for each of the 620 days of irradiation to calculate the release of silver, cesium, and strontium from a representative particle for a select number of AGR-1 compacts. Post-irradiation examination measurements provided data on release of these fission products from fuel compacts and fuel particles, and retention of silver in the compacts outside of the silicon carbide (SiC) layer. PARFUME-predicted fractional release of silver, cesium, and strontium was determined and compared to the PIE measurements. For silver, comparisons show a trend of over-prediction at low burnup and under-prediction at high burnup. PARFUME has limitations in the modeling of the temporal and spatial distributions of the temperature and burnup across the compacts, which affects the accuracy of its predictions. Nevertheless, the comparisons on silver release lie in the same order of magnitude. Results show an overall over-prediction of the fractional release of cesium by PARFUME. For particles with failed SiC layers, the over-prediction is by a factor of up to 3, corresponding to a potential over-estimation of the diffusivity in uranium oxycarbide (UCO) by a factor of up to 250. For intact particles, whose release is much lower, the over-prediction is by a factor of up to 100, which could be attributed to an overestimated diffusivity in SiC by about $40 \%$ on average. The release of strontium from intact particles is also over-predicted by PARFUME, which also points towards an over-estimated diffusivity of strontium in either SiC or UCO, or possibly both. The measured strontium fractional release from intact particles varied considerably from compact to compact, making it difficult to assess the effective over-estimation of the diffusivities. Furthermore, the release of strontium from particles with failed SiC is difficult to observe experimentally due to the release from intact particles, preventing any conclusions to be made on the accuracy or validity of the PARFUME predictions and the modeled diffusivity of strontium in UCO.
\end{abstract}

\section{INTRODUCTION}

Post-irradiation examination measurements were compared to model predictions of silver, cesium, and strontium release from selected tristructural isotropic (TRISO) fuel particles and compacts during the first irradiation test of the Advanced Gas Reactor (AGR) program (AGR-1).

The modeling was performed using the particle fuel model computer code PARFUME (PARticle FUel ModEl) developed at Idaho National Laboratory (INL). PARFUME is an advanced gas-cooled reactor fuel performance modeling and analysis code [1]. It has been developed as an integrated mechanistic code that evaluates the thermal, mechanical, and physico-chemical behavior of fuel particles during irradiation to determine the failure probability of a population of fuel particles given the particle-to-particle statistical variations in physical dimensions and material properties that arise from the fuel fabrication process, accounting for all viable mechanisms that can lead to particle failure.

The code also determines the diffusion of fission products from the fuel through the particle coating layers, and through the fuel matrix to the coolant boundary. The subsequent release of fission products is calculated at the compact level (release of fission products from the compact) but it can also be assessed at the particle level. 
Furthermore, the diffusivity of each layer can be individually set to a high value (typically $10^{-6} \mathrm{~m}^{2} / \mathrm{s}$ ) to simulate a failed layer with no capability of fission product retention. In this study, in order to more accurately reproduce the number of particles with non-retentive coating layers potentially observed in PIE, or lack thereof, it was decided to model intact particles and particles with failed layers separately. The resulting respective release fractions were then combined accordingly in each compact to compare to the measured release data.

During the AGR-1 irradiation campaign, the fuel kernel produced and released some fission products, which migrated through the successive layers of the TRISO-coated particle and through the compact matrix. The fission products of interest include silver, because it can plate-out in the colder parts of the reactor and become a safety hazard for maintenance workers, and cesium and strontium, which both have isotopes that would be radiologically hazardous if released following a nuclear accident in a reactor using TRISO fuel. The release of these fission products was measured in post-irradiation examination (PIE) and modeled with PARFUME. PARFUME calculates the release fraction as the ratio of the number of atoms released from the compact to the amount produced in the compact fuel kernels and through uranium contamination. The silver, cesium, and strontium release fractions determined by both PIE and PARFUME for selected compacts, and TRISO-coated particles in the case of silver, were then compared.

\section{AGR-1 IRRADIATION AND POST-IRRADIATION EXAMINATION}

The Department of Energy (DOE) Advanced Gas Reactor Fuel Development and Qualification program was established to qualify TRISO fuel for use in High Temperature Gas Reactors (HTGRs). The primary goal of the program is to provide a baseline fuel qualification data set in support of the licensing and operation of an HTGR [2].

AGR-1 is the first of these irradiation tests. Irradiation began in the Advanced Test Reactor (ATR) at INL in December 2006 and completed in November 2009. AGR-1 was intended to serve as a shakedown test of a multicapsule design to be used in subsequent irradiations, and to test early variants of the fuel produced under the DOE AGR program [3]. A total of 72 compacts were irradiated in the AGR-1 experiment in six different capsules. The experiment completed 620 effective full power days (EFPDs) in the reactor and achieved calculated peak burnup of $19.6 \%$ fissions per initial heavy metal atom (FIMA) and fast neutron fluence of $4.30 \times 10^{25} \mathrm{n} / \mathrm{m}^{2}(\mathrm{E}>0.18 \mathrm{MeV})[4]$.

At completion of the irradiation, PIE and high temperature safety testing were conducted. The objectives of the AGR-1 PIE and associated safety testing are to assess the overall performance of the test train and components and provide data to verify the test train thermal analyses, verify the particle coating integrity and evaluate the fission product retention of the fuel during normal irradiation and during high temperature postirradiation safety tests, and characterize the fuel compacts and individual particles to assess the condition of the matrix material, kernels, and coatings [5].

The results of the AGR-1 PIE are discussed in detail in Ref. [6]. As described in Ref. [6], information on fission product release was obtained through a number of different measurements. The primary means of assessing the level of fission product release was through direct analysis of the released inventory, which included the inventory released from particles but retained in the compacts outside of the silicon carbide (SiC) layer and the inventory released from the compacts and measured on the irradiation capsule components. Silver represents a special case, in which the level of release can be sufficiently high (i.e., in excess of several percent) that the fraction retained can be estimated by measuring the remaining inventory in the fuel. In all cases, the measured inventory was first decay-corrected to the end of the AGR-1 irradiation and then compared with the predicted inventory from as-run neutronics calculations of the AGR-1 experiment [7] to calculate corresponding release or retention fractions.

The PIE data on silver, cesium, and strontium release used for comparison with PARFUME predictions originate from the following measurement techniques [6]:

- Gamma scanning of 56 irradiated AGR-1 compacts was used to determine their fission product inventory. The measured Ag-110m inventory was compared to the predicted inventory to determine the extent of in-pile silver release. The irradiation characteristics of these compacts are shown in Figure 1 (black dots) and detailed in Ref. [8]. 
- Deconsolidation-leach-burn-leach (DLBL) analysis was used on nine compacts to determine the inventory retained within the compact outside of the $\mathrm{SiC}$ layer following irradiation. The irradiation characteristics of these compacts are detailed in Ref. [8] and reported in Table 1.

- Individual particles from these nine deconsolidated compacts were gamma counted in order to quantify their fission product inventory. In the case of $\mathrm{Ag}-110 \mathrm{~m}$, the measured inventory was compared to the predicted inventory to determine the extent of in-pile silver release.

- The inventory of fission products on the AGR-1 capsule components was measured to determine the level of release from the fuel compacts during irradiation.

The inventory of cesium and strontium released from the particles was taken to be the sum of the inventory found in the compacts outside of the SiC layer (i.e., in the outer pyrolytic carbon (OPyC) and matrix, based on DLBL measurements) and the inventory found outside of the compacts on the capsule components.

The retained inventory of silver in particles and compacts was determined directly based on measurement of the inventory remaining in the fuel. The retained fraction was obtained by dividing the measured inventory by the calculated inventory. The release fraction was then determined by subtracting the retained fraction from 1.

Additionally, silver release from particles was also assessed from potential retention of silver in the matrix. Since compact gamma scanning does not discriminate between the silver inventory in the particles and in the compact matrix, other techniques were employed to measure silver inventory in the matrix:

- DLBL data from the nine compacts listed in Table 1 provided a direct measure of Ag-110m outside the SiC layer.

- Results from the AGR-1 safety testing [9] were also used to assess silver matrix content by assuming that the prompt release of silver observed at the beginning of the heating tests originates from silver already present in the matrix at the end of irradiation. This assumption is discussed in further detail in Ref. [9].

The PIE data necessarily includes the contribution of fission products generated by fission of uranium contamination in the coating layers and in the matrix, but since the uranium contamination for AGR-1 compacts was on average lower than $4 \times 10^{-7}$ for each fuel variant, any release significantly above this level was attributed to release from the particles.

\section{PARFUME MODELING}

\subsection{AGR-1 Geometry and Fuel Characteristics}

The AGR-1 test train contains six capsules arranged vertically. Each AGR-1 capsule contains 12 fuel compacts arranged in three vertical stacks with each stack containing four compacts, as seen in Figure 2. Each compact is uniquely identified in the format $\mathrm{X}-\mathrm{Y}-\mathrm{Z}$, where $\mathrm{X}$ indicates the capsule, $\mathrm{Y}$ the axial level within the capsule, and $\mathrm{Z}$ the stack.

AGR-1 compacts are right cylinders nominally $25.1 \mathrm{~mm}$ in length and $12.4 \mathrm{~mm}$ in diameter. Each compact contains $\sim 4,150$ fuel particles uniformly dispersed in a matrix composed of a thermosetting carbonaceous material. Each particle consists of a kernel composed of a heterogeneous mixture of uranium carbide and uranium oxide (referred to as uranium oxycarbide or UCO; diameter $\sim 350 \mu \mathrm{m}$ ) coated with layers of porous carbon buffer $(\sim 100 \mu \mathrm{m})$, inner pyrolytic carbon (IPyC, $\sim 40 \mu \mathrm{m})$, silicon carbide $(\sim 35 \mu \mathrm{m})$, and outer pyrolytic carbon $(\sim 40$ $\mu \mathrm{m})$ layers. AGR-1 fuel comprises a baseline fuel and three fuel variants, with each variant fabricated by varying the deposition parameters for either the IPyC or SiC layer, resulting in minor differences in properties for that layer. Detailed fuel characteristics of the AGR-1 fuel can be found in Ref. [3].

\subsection{Boundary and Initial Conditions}

PARFUME is designed to evaluate fuel performance based on user inputs for fast neutron fluence and burnup with a corresponding set of thermal conditions. The neutronics and thermal conditions for all the compacts used for comparison to PIE measurements are based on results obtained from as-run neutronics calculations and as-run thermal analysis [7, 10]. The PARFUME calculations were computed prior to completion of PIE, and they are based on an earlier version of the as-run neutronics calculations [11]. The difference between the two sets of calculations is on burnup values, and it does not exceed a $1.2 \%$ relative deviation. Therefore, there is negligible impact on the calculated results. All subsequent plots show the burnup values used in PIE analysis. 
PARFUME assumes that all particles in a compact experience similar irradiation and thermal histories over the course of irradiation. Practically, PARFUME models one particle using the average burnup and fast neutron fluence and the volume-average temperature of the whole compact. The thermal history evolves on a daily basis. For each compact, the daily temperatures of all the calculation nodes are averaged [10], and PARFUME uses the resulting volume-average compact daily temperatures to set the thermal history of the modeled TRISO particle. The daily temperatures are set as boundary conditions at the outer edge of the OPyC. From the OPyC boundary temperature, PARFUME calculates the temperature profile between the OPyC and the kernel center. The daily temperatures were used in the modeling because the time-average volume-average (TAVA) temperatures were determined to not be a suitable metric to correlate fission product release to temperature (see Section 4.4.2).

\subsection{Input Parameters}

The input parameters needed to model the AGR-1 irradiation with PARFUME originate from the AGR-1 Irradiation Experiment Test Plan [3] for the fuel characteristics, particle geometry, compact characteristics, and material non-mechanical properties, and from a CEGA Corporation report [12] for the material mechanical properties. In addition, as-run neutronics calculations and as-run thermal analysis are used for the boundary conditions (see Section 3.2).

PARFUME models the transport of metallic fission products as a transient diffusion process described by Fick's laws of diffusion. The diffusion coefficients used for fission product transport are derived from the International Atomic Energy Agency (IAEA) Technical Document 978 [13] and displayed in Table 2. Because of the lack of published data for UCO kernels, $\mathrm{UO}_{2}$ diffusion coefficients are used by PARFUME for UCO kernels. The corresponding diffusivities can be calculated using these diffusion coefficients in the following Arrheniustype equation:

$\mathrm{D}=\mathrm{D}_{0} \mathrm{e}^{-\frac{\mathrm{Q}_{\mathrm{p}}}{\mathrm{RT}}}$

where $\mathrm{D}_{0}$ is a pre-exponential factor $\left(\mathrm{m}^{2} / \mathrm{s}\right), \mathrm{Q}_{0}$ is the activation energy $(\mathrm{J} / \mathrm{mol}), \mathrm{R}$ is the universal gas constant $(8.3145 \mathrm{~J} / \mathrm{mol} / \mathrm{K})$, and $\mathrm{T}$ is the temperature $(\mathrm{K})$.

The modeling of fission product transport as Fickian diffusion is an approximation of a more complex transport process that, in particular, depends on the microstructure of the fuel materials and that may involve several mechanisms such as lattice diffusion, grain boundary diffusion, pore diffusion, nano cracks, vapor transport, etc. Furthermore, effects like irradiation-induced trapping and adsorption, thermal decomposition of the coating layers, or chemical attack of these coating layers by other fission products such as palladium or rare earth elements potentially impact these transport mechanisms. Therefore, diffusion coefficients used in PARFUME are implicitly defined as "effective", implying that they describe the overall fission product transport using classical Fickian diffusion [14].

PARFUME calculates fission product release at the compact or particle level [1]. This allows for a comparison of modeling predictions to the various PIE measurements: fission product retention in the compacts as measured by gamma scanning (for silver only), or fission product release from individual particles as obtained by directly gamma counting particles or by combining the inventory in the compact outside of SiC (DLBL data) with the inventory released from compacts in each capsule (capsule component inventory data).

Release from particles with failed layers can be obtained by setting the diffusivities in these layers to a high value of typically $10^{-6} \mathrm{~m}^{2} / \mathrm{s}$. In these calculations, PARFUME models the fission product release from intact particles and from particles with both failed IPyC and SiC layers. The modeling assumed that the failure of the $\mathrm{SiC}$ layer occurred immediately after the failure of the IPyC layer. The failures of the coating layers were assumed to occur at the beginning of irradiation. The assumption of coating failures occurring at the beginning of irradiation results primarily from two observations. First, the monitoring of fission product gas release concluded that no fuel particle failures occurred during the AGR-1 irradiation [4]; therefore, there is no experimental data to set a failure time for modeling purposes. Second, modeling of the AGR-1 irradiation predicted zero particle failures and the maximum failure probability was predicted after about 70 days of irradiation when the fuel had been at high temperature for only about a day (fuel temperature history is discussed in Section 4.4.2). Therefore, there is no appreciable difference in the total release of fission products over 620 EFPD when the failure occurred at the start of the irradiation or 70 days into the irradiation. Following PARFUME calculations, the modeling results were then compared to the measured release data. 


\section{SILVER RELEASE}

\subsection{Compact Gamma Scanning}

The silver release fractions derived from PIE measurements $[6,15]$ and PARFUME predictions for the 56 selected compacts are displayed in Figure 3. The data points are plotted according to the AGR-1 capsule in which they were irradiated with the top of the experiment (Capsule 6) on the left and bottom (Capsule 1) on the right. For each capsule, the compacts are plotted from the left for Stack 3 to Stack 1 and a decreasing axial level within each stack. Negative fractional release indicates apparent bias in the measured PIE values or, more likely, in the predicted inventories.

From Figure 3, the following observations can be made:

- PARFUME under-predicts the PIE data in Capsules 1 and 6.

- PARFUME under-predicts the PIE data in Capsule 5 on average.

- PARFUME over-predicts the PIE data in Capsules 2 and 3.

- PARFUME mostly over-predicts the PIE data in Capsule 4.

Since the burnup of the AGR-1 fuel was higher in the middle capsules than it was at the ends, these observations indicate that PARFUME under-predicts PIE data in the lower burnup capsules (end capsules) and over-predicts PIE data in the higher burnup capsules (middle capsules).

\subsection{Particle gamma counting}

Typically 40 to 120 particles per compact were selected for gamma counting. The silver retention fraction was determined for each particle by calculating the ratio of the measured Ag-110m inventory to the predicted inventory. The predicted inventory for each particle was determined by dividing the total predicted inventory for the compact by the average number of particles per compact, and normalizing this value based on the Cs-137 inventory in each particle to account for particle-to-particle variation in fissile content and burnup (as described in Ref. [6]). The average particle retention fraction for each compact was then calculated by averaging the individual particle values. The average silver release fraction per particle was then compared to the values calculated by PARFUME.

PIE results [6] and PARFUME results are displayed in Figure 4. Similar to the compact gamma scanning comparisons, PARFUME over-predicts release in Capsules 3 and 4, and it under-predicts release in Capsules 1, 5 and 6. PIE data for Compacts 1-3-1, 5-2-1, 5-2-3, 5-3-1, and 6-3-2 show a range that accounts for uncertainty in the average particle retention fraction due to several gamma-counted particles from each compact exhibiting Ag$110 \mathrm{~m}$ inventory below the detection limit (see Ref. [6] for more details).

\subsection{Silver Matrix Content}

Sections 4.1 and 4.2 showed reasonable agreement between PIE and PARFUME for silver release from compacts or particles. In the case of PARFUME, the calculated release from particles or from their host compact is essentially identical because of the high diffusivity assumed for silver in the matrix material (see Table 2). Direct PIE measurements performed by deconsolidation leach-burn-leach on the compacts in Table 1 showed that the amount of silver outside the $\mathrm{SiC}$ layer (referred to here as "matrix content", even though the experimental technique cannot distinguish between inventory in the $\mathrm{OPyC}$ or in the matrix) is generally limited to a few percent of the silver inventory or less, with the exception of Compact 6-1-1, whose silver matrix content reaches $12 \%$ [6]. On the other hand, results from the AGR-1 safety testing experiments [9] showed on a few occasions a high release of silver, up to $\sim 30 \%$, in the first hours of the tests. In these safety tests, selected compacts were heated to temperatures ranging from 1600 to $1800^{\circ} \mathrm{C}$ and held for about 300 hours. Released silver was then collected on deposition cups every 24 hours. It is believed that the prompt release observed in the early stage of all the tests comes primarily from silver that was released from particles during the irradiation but retained within the compacts outside of the $\mathrm{SiC}$ layer, and subsequently rapidly released when the compacts were heated above $1250^{\circ} \mathrm{C}$ in the safety tests [9]. To a first approximation then, this rapid silver release is taken as a measure of silver outside of the $\mathrm{SiC}$ layer in the compacts, comparable to the DLBL measurements. 
The silver matrix content was assessed for the 17 compacts listed in Table 3 [8]. These are compacts for which data on both Ag-110m in the compact matrix (either from DLBL measurement or inferred from safety test data) and total compact Ag-110m inventory (from compact gamma scanning) were available. Hypothetically, subtracting the measured inventory in the matrix from the total compact inventory gives an assessment of the average fractional release from the particles, which is compared to PARFUME in Figure 5. In Figure 5, the data labeled "PIE" is based solely on the total compact inventory data (from gamma scanning) and is identical to that presented in Figure 3 for these specific compacts. The data labeled "Corrected PIE" has been determined as described in this paragraph (i.e., correcting the total compact inventory by the amount estimated to be present in the compact outside the SiC layer at the end of irradiation). PARFUME does not predict any silver retention outside the $\mathrm{SiC}$ layer, hence the predicted releases from the particles and compact are essentially identical, and therefore only one set of values is presented. The numbering of the compacts in Figure 5 follows the order of Table 3, starting with Compact 6-4-3 on the left.

Figure 5 shows that the previously observed trends of under/over-predictions are mostly not modified by the correction of the matrix content. In the case of under-prediction, the discrepancy between PIE and PARFUME is increased, while in the case of over-prediction, the corrected PIE results are closer to the PARFUME results. The exception is Compact 4-3-3 (\#10 in Figure 5) that goes from being over-predicted to being under-predicted.

Because of the high silver diffusivity assumed in the matrix material, PARFUME does not predict any retention in the matrix, but AGR-1 PIE data show that retention in the matrix can be significant, suggesting that the matrix graphite material might be more retentive than predicted based on diffusion coefficients from Ref. [13].

\subsection{Discussion and Analysis on Silver Release}

\subsubsection{Impact of Temperature on Silver Fractional Release}

As mentioned in Section 3.2, TAVA temperatures are not a suitable metric to correlate silver release to temperature because they do not adequately reflect the thermal state of the compacts throughout irradiation. Daily temperatures were therefore used to calculate the predicted silver release. In addition to their distribution around the compact TAVA temperature, daily temperatures also widely vary spatially throughout a compact with a typical spread of several hundred degrees from the cold side to the hot side of a compact [10]. This can lead to a significant range in silver release from one particle to the other.

Because of the large number of thermal nodes ( 3500 thermal nodes, each one roughly corresponding to one TRISO particle), PARFUME was not used to calculate the silver release of every single node. The predictions for silver release are based on the behavior of an average particle within each compact, whereas PIE measurements reflect the behavior of individual particles experiencing a broader set of daily temperatures because of their spatial locations all over the compact (in the case of compact gamma scanning) or at various locations whose daily temperatures might significantly differ from the compact average (in the case of particle gamma counting).

To address the issue of spatial distribution and assess the impact of temperature distribution across a compact, all the thermal nodes of Compact 6-3-2 were examined to determine the cold and hot nodes of the compact, defined as the nodes that have the minimum and maximum calculated silver release fractions, respectively, over the entire course of irradiation. These cold and hot nodes are used to represent the coldest and hottest particles in Compact 6-3-2.

Figure 6 illustrates the calculated silver release as a function of time for the cold and hot particles in Compact 6-3-2 during the AGR-1 irradiation. The nominal value is obtained using the volume-average daily temperatures of the compact.

The calculations show that particles from Compact 6-3-2 are predicted to release between 9\% (cold particle) and $67 \%$ (hot particle) of their silver, with a nominal value of $41 \%$. The predicted release from Compact 6-3-2 is compared to PIE in Figure 7, where the retained fraction (1 - release fraction) is displayed, as the inventory of Ag- $110 \mathrm{~m}$ remaining in the particle is measured by gamma counting.

Because of the gamma counting detection threshold, Figure 7 shows the distribution of particles with detectable silver and adds the contribution of particles for which the Ag-110m activity was below the detection limit (where the detection limit was used as a conservative upper bound for the Ag-110m activity). For Compact 6-3-2, the measured distribution of retained silver spans from 8 to $88 \%$ which almost encompasses all of the 
predicted range of 33 to $91 \%$. The agreement between PARFUME and PIE is not as close on Compact 1-3-1 for which the measured and predicted ranges are displayed in Figure 8. The measured Ag-110m retention fraction ranges from 6 to 53\%, while the PARFUME prediction ranges from 64 to 98\%, showing a significant offset although the widths of both ranges are somewhat comparable.

The discrepancy observed between PARFUME and PIE when comparing the average fractional release (or retained fraction) can be largely attributed to the wide distribution of temperatures experienced by a compact during irradiation. PARFUME uses the volume-average daily temperatures to compute the average fractional release for each compact, while gamma measurements are performed on a subset of particles whose exact irradiation history is not known because information regarding the original location of the particles in the compact was lost during the deconsolidation. Furthermore, in the case of PARFUME, the release fraction of a particle bearing the volume-average daily temperatures is not equivalent to the average of the release fractions of all individual particles in the compact because the diffusivity does not vary linearly with temperature (see Eq. 1). Therefore, using the volume-average daily temperatures under-estimates the release by neglecting the relatively larger release of hotter particles.

As-run calculations report uncertainties on the calculated temperatures up to $100^{\circ} \mathrm{C}$ [4]. Although no temperature bias was reported, Figure 9 shows the impact of a temperature change on the silver release calculated by PARFUME. For each of the 56 gamma scanned compacts, the temperature was adjusted in PARFUME calculations to attempt to match the PIE release using a trial and error method. The temperature was adjusted in increments of $\pm 25^{\circ} \mathrm{C}$ until the PARFUME prediction best matched the PIE value for each compact, and the adjusted PARFUME values are presented in Figure 9 according to the magnitude of the temperature adjustment. For instance, the daily temperatures of Compact 6-2-3 (first from the left) were adjusted by $+200^{\circ} \mathrm{C}$, the adjustment was $+50^{\circ} \mathrm{C}$ for Compact 6-1-3 (second from the left), and so forth. Consequently, most compacts are attributed three data points: PIE release fraction, initial PARFUME release fraction, and temperature-adjusted PARFUME release fraction. If no temperature adjustment was needed, i.e., an adjustment of $\pm 25^{\circ} \mathrm{C}$ did not improve the agreement between PARFUME and the PIE value, there are only two data points displayed (PIE and initial PARFUME release fractions). The minimum temperature change was limited to $-100^{\circ} \mathrm{C}$ as PARFUME cannot calculate negative release fractions as assessed by PIE. Figure 9 shows that in most cases the PARFUME/PIE comparison can be significantly improved by a temperature adjustment of $100^{\circ} \mathrm{C}$ or less.

Figure 10 plots the temperature adjustment required for each compact to have PARFUME calculations match PIE measurements on silver release. Most of the $-100^{\circ} \mathrm{C}$ adjustments are meant to match PIE release fractions lower than $2 \%$. At these low release levels, larger negative adjustments would not significantly improve the estimated release fractions. Therefore, the value of $-100^{\circ} \mathrm{C}$ is chosen as a cut-off value beyond which no further improvement can be obtained by arbitrarily decreasing the temperature adjustment. Furthermore, the bias in measured silver retention (see Section 4.1) creates negative release fractions that cannot be achieved by modeling. As a result, the temperature adjustment at low fractional release has to be limited to $-100^{\circ} \mathrm{C}$ as it loses its significance for temperature adjustments beyond that cut-off. Table 4 shows the repartition of these temperature adjustments by capsule. It shows that the largest positive adjustments are needed for Capsules 1 and 6, for which the discrepancy between PARFUME and PIE on silver fractional release is the largest (see Figure 3). Conversely, the largest negative adjustments are needed for Capsules 2, 3, and 4. It can be noted that the majority of the temperature adjustments fall within the range of uncertainties reported on the as-run calculated temperatures.

\subsubsection{Impact of Burnup on Silver Fractional Release}

The silver release is also impacted by burnup as can be seen in Figure 11. Figure 11 shows that the silver fractional release decreases with burnup, which can be correlated with the temperature of the compacts throughout irradiation. Figure 12 displays the correlation between burnup and the time-average volume-average temperatures calculated over the full 620 days of irradiation and calculated over the last 310 days of irradiation. It demonstrates that the temperature in the compacts was globally higher in the second half of irradiation compared to the first half and that the lower burnup compacts tended to have higher temperatures during the second half of irradiation. This is easily explained by considering that the lower burnup compacts had more fissile material inventory towards the end of irradiation than higher burnup compacts and, therefore, they had higher fission rates which ultimately led to higher heat generation rates and, consequently, higher temperatures. 
The larger release of silver is obtained when high temperatures force the diffusion of a large amount of silver through the TRISO particle. This is typically the case towards the end of irradiation, when the silver source has accumulated significantly with time, and only if the temperature of the compact is high enough. Because compacts with lower burnup became hotter towards the end of irradiation, they yielded a higher silver release on average.

As an illustration, PARFUME calculations show in Figure 13 that Compact 4-3-2 (final burnup of 16.38\% FIMA) produced less silver than Compact 4-4-1 (18.96\% FIMA), which is expected since silver production is a function of burnup. Nevertheless, Compact 4-3-2 yielded a higher PIE silver release fraction (42\%) than Compact 4-4-1 (3\%) based on compact gamma scanning because its daily temperatures were higher towards the end of irradiation. Figure 13 also shows that Compacts 4-4-1 and 4-3-2 both have a TAVA temperature of $1057^{\circ} \mathrm{C}$, which gives no indication about their respective silver release fractions and, therefore, demonstrates the problem with using TAVA temperature as a metric to correlate fission product release to temperature.

Figure 14 shows the difference in silver release fractions between PARFUME predictions and PIE measurements as a function of burnup. A slight trend can be drawn in the observed under-prediction at low burnup and over-prediction at high burnup. As seen in Figure 11, both PIE data and PARFUME exhibit the trend of a higher release at low burnup, but the trend seems more marked in the case of PIE data. The issue of temperature spatial distribution discussed above can possibly explain the observed trend but a direct burnup effect not captured by PARFUME cannot be ruled out.

\subsubsection{Impact of the Source on Silver Fractional Release}

The release of silver is primarily driven by temperature. Section 4.4.1 showed that there is some uncertainty in the prediction of silver release because of the temperature spatial distribution across the compacts. As-run neutronics calculations showed that irradiated compacts also had burnup spatial distributions across the compact [7], which impacts the distribution of the silver source.

PARFUME calculates the release fraction of an average particle bearing the volume-average burnup of its host compact. This calculated release fraction from an average particle is different from the average release fraction of all the compact particles whose burnups vary around the average compact burnup, which is the release fraction derived from PIE measurements using as-run neutronics source calculations. Therefore, variations of burnup across the compact create a discrepancy between the calculated release fractions and the release fractions derived from PIE measurements.

These variations in burnup depend on the exact location of the compact in the test train. For burnup, rough estimates based on physics simulations of the AGR-1 experiment and burnup measurements on the irradiated compacts suggest that a value of $\pm 25 \%$ is bounding for the compacts considered in this study and was thus used in this analysis. For a given irradiation time, a faster building burnup is obtained from a higher heat rate in the kernel and produces a larger swelling of the kernel in the PARFUME model. The former leads to a higher temperature in the kernel, which enhances silver diffusion, while the latter provides more diffusion barrier by effectively adding more kernel material to diffuse through in the model. Note that, even though the diffusion process might accelerate with decreasing kernel density, the IAEA diffusivities used in PARFUME do not depend on density; therefore, the PARFUME modeling does not capture this potential effect. Table 5 shows the impact of a burnup variation of $\pm 25 \%$ on the calculated silver release fraction for Compact $4-3-2$, if all other irradiation characteristics are kept equal. It shows that the silver release fraction slightly decreases with burnup. The silver source is proportional to the $3 / 2^{\text {th }}$ power of burnup [8], leading to a decrease of the release fraction with burnup because the source builds up faster than the release of silver, whose diffusion is controlled by the two antagonist effects of kernel swelling and kernel temperature increase. This decrease of silver release fraction with burnup is very limited and it cannot account for the discrepancy observed between PARFUME predictions and PIE measurements.

PARFUME calculates the fractional release of silver independently of its isotopes. This is because an effective fission product yield used for silver was calculated to reflect the overall production of all silver isotopes with burnup, and is largely dominated by Ag-109. Additionally, it is assumed that all silver isotopes behave similarly with respect to diffusion through the TRISO particles and matrix. On the other hand, PIE measures the release of $\mathrm{Ag}-110 \mathrm{~m}$, which is produced by neutron activation of Ag-109. Figure 15 shows that the production of Ag-110m, calculated by as-run neutronics, has a different burnup dependence compared to the production of Ag- 
109. Because Ag-110m originates from Ag-109 and is not an independent source of silver, the release fractions of both isotopes are the same, provided that both isotopes behave similarly in regards to diffusion. Practically, PARFUME calculates the production and release of elemental silver, a fraction of which is activated into Ag$110 \mathrm{~m}$ whose release is measured by PIE. Therefore, the magnitudes of both isotopes sources are different, the Ag-110m source much smaller than the Ag-109 source. However, the relative magnitude of the source does not have any impact on the release fraction, as a fraction " $x$ " of a given source produces a fraction " $x$ " of its release, leaving the release fraction unchanged. In this case, a fraction of the produced Ag-109 activates into Ag-110m which provides a release that is the same fraction of the released Ag-109. As a result, the release fraction of Ag$110 \mathrm{~m}$ is identical to the release fraction of silver as a whole, or of its main isotope Ag-109. Consequently, there is no additional source of discrepancy caused by comparing PARFUME's release fractions of (mainly) Ag-109 and PIE's release fractions of Ag-110m.

\section{CESIUM AND STRONTIUM RELEASE}

\subsection{Comparison to PIE Data}

DLBL was performed on the nine compacts listed in Table 1 (see Section 2). For compacts containing all intact particles, the DLBL measurement includes the contribution from the amount of fission products released through intact coatings but retained in the compact outside of the SiC layer, as well as fission products from uranium contamination in the $\mathrm{OPyC}$ and the compact matrix. As mentioned in Section 2, the uranium contamination in AGR-1 compacts was on average lower than a fraction of $4 \times 10^{-7}$ for each fuel variant so any release significantly above this level can be assumed to come from other sources. The DLBL data therefore represents a partial inventory of fission products released from intact particles, as it does not account for fission products released from the compacts and found on capsule components. In PARFUME, the uranium contamination is modeled in the OPyC layer. Because of the relatively high diffusivities of cesium and strontium in PyC (see Table 2), the inventory produced by uranium contamination is predicted to be almost instantaneously released.

If any particles with failed $\mathrm{SiC}$ are present - and the particles are not removed from the population before the burn-leach is performed - then the inventory of the kernels from these particles will also be included in the postburn leach solutions, and may greatly exceed the level of fission products attributed to diffusive release through coatings. In addition, in compacts containing particles with failed $\mathrm{SiC}$, these particles contribute to the total inventory on the compact outside of the $\mathrm{SiC}$ layer, and therefore the DLBL values do not represent release from intact particles exclusively.

Based on analysis of fission products in the capsule components [16], it was determined that compacts 6-3-2, 5-2-3, and 5-2-1 may have one or more particles with a non-retentive SiC layer. DLBL results from Compact 6-3-2 indicated the presence of one such particle, the kernel of which was dissolved during post-burn leaching (and therefore the DLBL totals include the contribution from this kernel) [6].

Gamma analysis of particles from Compact 5-2-3 revealed that this compact contained two particles with failed SiC. Compact 5-2-1 was determined to have one such particle. In both cases, these particles were removed from the population before DLBL analysis, and so the remaining inventory in the kernels was not dissolved during the DLBL process [17].

Two sets of calculations were performed with PARFUME. The first set calculates the diffusive release from intact particles. It is used in particular to calculate the release of cesium and strontium from compacts containing intact particles only. The second set calculates the diffusive release from particles with failed IPyC and SiC layers and intact OPyC layers in the compacts found to contain such particles. For these compacts, the second set can be used alone or combined with the first set depending on PIE findings. Because PIE measurements indicate very little cesium release from intact particles, the second set of calculations is intended to directly compare PARFUME predictions of release from particles with failed $\mathrm{SiC}$ to PIE measurements in cases where the particles with failed $\mathrm{SiC}$ will dominate the total release. Therefore, the second set alone is used for calculations of cesium release in compacts containing particles with failed SiC. However, PIE data indicate a non-negligible strontium release from intact particles. Thus all strontium calculations account for strontium released by intact particles because their contribution is not negligible when compared to the amount of strontium released by the particles with failed SiC. In this case, the two sets of calculations are combined to calculate strontium release in compacts containing particles with failed SiC. Table 6 gives a summary of these two sets of calculations and their application to cesium and strontium fractional release calculations. 
For each compact, the DLBL values were corrected to take into account the amount of cesium and strontium released from the compacts and collected on the capsule components. In most cases, this amount cannot be easily attributed to the specific compacts it originated from, so bounding values were determined. A lower bound assumes that none of the cesium and strontium found on the capsule components originates from the analyzed compact (label "Min" in Figures 16 and 17). In this case, the total release from the compact is assumed to be zero, and the release from the particles is equivalent to the inventory found in the compact outside of the SiC layers from DLBL data. On the other hand, an upper bound assumes that all of the cesium or strontium found on the capsule components originates from the analyzed compact ("Max"). In this case, the release from the compact is equivalent to the inventory found on the capsule components, and release from the particles is assumed to be the capsule component inventory plus the inventory found in the compact outside of the SiC layers from DLBL data.

In some cases, the contribution from fission product inventory on the capsule components could be assessed more accurately and attributed to one or more specific compacts [8]. This is specifically true for cesium release, where it was found experimentally that only particles with failed SiC contributed significantly to the inventory released from the compacts in capsules containing such particles. For example, in Capsule 5, Compacts 5-2-3 and 5-2-1 were found to contain particles with failed $\mathrm{SiC}$, and measurements indicated that the overwhelming majority of cesium found on the capsule components was from these two compacts (see Ref. [6] for further information); thus it can be assumed that Compact 5-3-1 (also from Capsule 5) contributed a negligible amount of cesium to the capsule component inventory. Similarly for Capsule 6, since Compact 6-3-2 was the only compact found to contain a particle with a failed SiC layer, it is assumed that Compact 6-1-1 contributed a negligible amount of cesium to the capsule component inventory. Consequently, for Compacts 5-3-1 and 6-1-1 only a "Min" value is displayed in the histograms, while for Compacts 5-2-1, 5-2-3, and 6-3-2 only a "Max" value is displayed.

The data are displayed in Figures 16 and 17. In these figures, "PARF Intact" represents the calculated release fractions of compacts containing intact particles only, and "PARF N Fail" represents the calculated release fractions of compacts containing $\mathrm{N}$ particles $(\mathrm{N}=1$ or 2$)$ with failed IPyC and SiC layers. In the case of cesium, "PARF N Fail" excludes the contribution from intact particles, and only represents the calculated release from the particles with failed $\mathrm{SiC}$, as indicated in Table 6. In the case of strontium, "PARF N Fail" represents the sum of the calculated release from intact particles and from particles with failed SiC. "PARF Intact" is also displayed in the figures corresponding to compacts containing particles with failed $\mathrm{SiC}$ to separately show the calculated contribution from the intact particles. The figures show that for both cesium and strontium the calculated release from intact particles is not negligible compared to the calculated release from particles with failed SiC, which is in disagreement with PIE data in the case of cesium.

\subsection{Sensitivity of Cesium and Strontium Release Fractions to Burnup and Temperature}

As-run neutronics calculations and as-run thermal analysis showed that irradiated compacts had burnup and temperature spatial distributions [7, 10]. Burnup variation across the compact impacts the distribution of the fission product source, while temperature variation impacts fission product transport and, therefore, release. PARFUME calculates the release fraction of an average particle bearing the irradiation characteristics of its host compact (volume-average burnup, fast fluence, and daily temperatures). This calculated release fraction from an average particle is different from the average release fraction of all the compact particles experiencing irradiation conditions varying around these average compact values, which is the release fraction derived from PIE measurements using as-run neutronics source calculations. Therefore, variations of burnup and temperature across the compact create a discrepancy between the calculated release fractions and the release fractions derived from PIE measurements. In this sensitivity study, burnup and temperature were treated independently of each other. Although as-run thermal calculations provide a detailed temperature map of each compact ( 3500 finite elements), as-run neutronics only provide two burnup values per compact. Therefore, the cross-influence of burnup and temperature has not been established in a way that would allow considering it in this modeling.

These variations in burnup and temperature depend on the exact location of the compact in the test train. For burnup, rough estimates based on physics simulations of the AGR-1 experiment and burnup measurements on the irradiated compacts suggest that a value of $\pm 25 \%$ is bounding for the compacts considered in this study and thus used in this analysis. For temperature, finer thermal calculations allow determining the cold and hot nodes of the compact, defined as the nodes that have the minimum and maximum calculated release fractions over the duration of the irradiation, respectively. Sensitivity of the release fraction from an intact particle to burnup and 
temperature was calculated on Compact 4-1-1, which has median release fractions for both cesium and strontium (see Figure 16a and 17a). Similarly, sensitivity of the release fraction to burnup and temperature was calculated on Compact 6-3-2 for a particle with failed $\mathrm{SiC}$.

For a given irradiation time, a faster burnup build-up is obtained from a higher heat rate in the kernel and produces a larger swelling of the kernel in the PARFUME model. The former leads to a higher temperature in the kernel, which enhances silver diffusion, while the latter provides more diffusion barrier by effectively adding more kernel material to diffuse through in the model. Table 7 shows the impact of a burnup variation of $\pm 25 \%$ on the calculated cesium and strontium release fractions from an intact particle in Compact 4-1-1 and a particle with failed SiC in Compact 6-3-2. The effect of burnup variation on fission product release is similar for an intact particle and a particle with failed $\mathrm{SiC}$ as it impacts the release from the kernel which is not affected by the integrity of the IPyC and $\mathrm{SiC}$ layers, or lack thereof. In the case of cesium, there is no significant impact of a variation of burnup because the source inventory is proportional to the burnup, so the $\pm 25 \%$ variation cancels out between the source build-up and the release when the release fraction is calculated. In the case of strontium, the source is proportional to the $4 / 5^{\text {th }}$ power of burnup [8], leading to an increase of the release fraction with burnup because the source does not build up as fast as the release. This increase is somehow limited and it cannot account for the discrepancy observed between PARFUME predictions and PIE measurements. Furthermore, the overall calculated strontium release from a compact is dominated by the release from intact particles so the impact of burnup variation on the release from particles with failed $\mathrm{SiC}$ is negligible when determining the overall release.

Table 8 shows the impact of temperature on the calculated cesium and strontium release from an intact particle in Compact 4-1-1 and from a particle with failed $\mathrm{SiC}$ in Compact 6-3-2. The release fractions were calculated for the average particle and for the cold and hot nodes of each compact as determined by thermal analysis. In the case of the cold node, the temperature is too low to allow diffusion of cesium or strontium through an intact $\mathrm{SiC}$ layer and the calculated release fractions for an intact particle correspond to the uranium contamination fraction (modeled in the OPyC layer in PARFUME) or lower. Strontium is partially retained by the kernel, which leads to a low release from a particle with failed $\mathrm{SiC}$. Conversely, cesium is not retained by the kernel and its release from a particle with failed $\mathrm{SiC}$ is significant even at lower temperatures. In the case of the hot node, the release fractions for an intact particle are increased for both cesium and strontium by a factor of about 30. Cesium and strontium release fractions from a particle with failed $\mathrm{SiC}$ are also larger at higher temperatures. In most compacts, the hot node is on average $100^{\circ} \mathrm{C}$, and up to $150^{\circ} \mathrm{C}$, hotter than the average node. Because of the exponential dependence of the diffusivity on temperature (see Eq. 1), fission product release is strongly influenced by relatively higher temperatures.

\subsection{Discussion and Analysis on Cesium and Strontium Release}

Figure 16a shows that PARFUME over-predicts the measured cesium release from intact particles by a factor of 2 to 100, with the exception of Compact 4-4-2 for which the predicted release is lower than the measured release by a factor of 2. For strontium, the PARFUME over-prediction for particles with intact SiC is by a factor of 5 to 400 except for Compact 1-3-1 where the calculated release is $20 \%$ lower than the measured release (see Figure 17a).

As seen in Section 4.2, the variation of burnup across compacts cannot account for the discrepancy between PARFUME predictions and PIE measurements. Furthermore, PARFUME should under-predict the average release fraction from all particles in a compact, as derived by PIE, because it does not capture the higher release fractions from the hotter particles. This ensues from the Arrhenius form of the diffusivities (see Eq. 1) which emphasizes the contribution from higher temperatures compared to lower temperatures. Considering the temperature distributions of the AGR-1 compacts, the average release of all particles at their own temperature is larger than the release of an average particle at the volume-average temperature because the former release is mostly caused by the hotter particles. Therefore, PARFUME over-prediction of the release of cesium and strontium indicates that the IAEA diffusivities of these species in SiC are too high at the AGR-1 irradiation temperatures.

Figure 16b shows that the contribution to the release of cesium from one or two particles with failed $\mathrm{SiC}$ is slightly over-estimated by PARFUME. The PARFUME predictions "PARF N Fail" in Figure 16b exclude the contribution of intact particles, as PIE showed that the release is dominated by the contribution of particles with failed SiC. A failed SiC layer gives direct access to the diffusivity in the kernel, assuming the PyC layers exhibit relatively low retention and that there is no holdup of cesium due to the formation of immobile species elsewhere 
within the particle. If these assumptions are correct, Figure 16b would then indicate that the IAEA diffusivity of cesium in the kernel is too high. This could also explain why the predicted cesium release is too high in intact particles, as shown in Figure 16a. It could therefore be expected that the diffusivity of cesium in UCO is lower than its diffusivity in $\mathrm{UO}_{2}$, the latter being used in the PARFUME modeling due to a lack of empirical data for $\mathrm{UCO}$, but potentially over-estimated $\mathrm{UO}_{2}$ diffusivities reported by the IAEA cannot be discarded. Based on Figure 16b, the predicted release fractions are about a factor of 1.3 (Compact 6-3-2) to 3 (Compact 5-2-3) higher than the PIE results, which at this level of cesium release corresponds to an over-estimation of the diffusivity of cesium in the kernel by a factor of about 25 to 250 .

Another possible explanation for the observed discrepancies between PARFUME and PIE could stem from the irradiation temperature. The probability of $\mathrm{SiC}$ failure is higher at lower temperatures when irradiationinduced creep in the PyC layers is not large enough to offset their shrinkage and to relieve the compressive stress in the $\mathrm{SiC}$ layer. Calculations of cesium release at lower temperatures using the cold nodes defined in section 4.2 show that the aforementioned predicted release fractions become equal to about 0.9 (Compacts 6-3-2 and 5-2-1) to 2.4 (Compact 5-2-3) times the release fractions derived by PIE. Assuming the SiC failures in these compacts occurred a colder temperature (cold node temperature rather than TAVA temperature), the predicted and measured release fractions would be in better agreement and there would be no systematic over-prediction of the cesium release from the kernel and no correction needed for the IAEA diffusivity of cesium in the kernel.

However, an additional possibility exists that cesium not fully released by particles with failed $\mathrm{SiC}$ is not entirely retained by the kernel, but is retained elsewhere in the particle, perhaps has an immobile compound formed with other fission products. This would partially invalidate the previous approaches, as the kernel might not be as retentive as PIE data seems to indicate.

One further reason for over-prediction of cesium release from particles with failed SiC by PARFUME could potentially be attributed to the timing of SiC failure as modeled by PARFUME. Because of the lack of information about the timing of $\mathrm{SiC}$ failure during irradiation, PARFUME takes a conservative approach and models the $\mathrm{SiC}$ failure from the very beginning of irradiation. Figure 18 shows the evolution of the cesium fractional release from a particle with failed $\mathrm{SiC}$ as a function of the time of failure. It shows that the release reaches about $100 \%$ at the end of irradiation independently of when the $\mathrm{SiC}$ failure occurred. Therefore, there is no over-prediction of cesium release due to considering an early failure rather than a later one.

In addition, although cesium release from intact particles is much lower than from particles with a failed $\mathrm{SiC}$ layer, the larger relative discrepancy between PARFUME calculations and PIE data on the release from intact particles would indicate that the diffusivity of cesium in SiC given by the IAEA is too high at the AGR-1 irradiation temperatures. Based on Figure 16a, and assuming no correction of the diffusivity in the kernel, the over-estimation of cesium diffusivity in SiC would range from $20 \%$ (Compact 3-2-1) to 60\% (Compact 4-1-1), with the largest agreement between PARFUME and PIE reached for a reduction of the IAEA diffusivity by about $40 \%$.

In the case of strontium, the available PIE data do not allow a conclusive assessment of the over-prediction of the diffusivities in the kernel or SiC layer since the respective contributions from intact particles and particles with failed SiC are not clearly separable. The PARFUME predictions in Figure 17b include the contribution of intact particles, as PIE showed it was not negligible compared to the release from particles with failed SiC. Figure 17a shows a large over-prediction of the release from intact particles in most cases (with the exception of Compact 1-3-1). This over-prediction is also evident in Figure 17b for Compact 6-3-2, though it is much more limited for Compacts 5-2-1 and 5-2-3. Figure 17b shows that the release fraction of strontium from Compact 5-23 particles derived by PIE is about $0.3 \%$. The contribution to the release fraction from particles with failed SiC cannot exceed approximately $4.8 \times 10^{-4}$, corresponding to two failed particles out of $\sim 4150$ in the compact. Therefore, most of the measured release from Compact 5-2-3 particles comes from the intact particles. Similarly, the strontium release fraction from the particles of Compact 5-2-1 determined by PIE is approximately $0.16 \%$, which significantly exceeds the maximum possible contribution from the single particle with failed $\mathrm{SiC}$ (approximately $2.4 \times 10^{-4}$, corresponding to one particle out of $\sim 4150$ in the compact). Such a high release from intact particles would be consistent with the release observed from Compact 1-3-1 particles (see Figure 17a) but it does not offer any indication about strontium release from particles with failed $\mathrm{SiC}$. In this case, the overprediction observed on the release from intact particles can be attributed to an over-estimation of the effective diffusivity of strontium in $\mathrm{SiC}$, or in $\mathrm{UCO}$, or both. It would also be possible that one diffusivity is over-estimated while the other one is under-estimated, the larger magnitude of the over-estimation leading to the overall overprediction of the release. 


\section{CONCLUSION}

The PARFUME modeling code was used to predict silver, cesium, and strontium release from TRISO-coated fuel particles and compacts during the AGR-1 irradiation, and compare the predictions to PIE measurements.

For silver, post-irradiation examination measurements were made by gamma scanning of 56 compacts and gamma counting individual particles from nine deconsolidated compacts. For cesium and strontium, PIE measurements were made by deconsolidation-leach-burn-leach of nine compacts and measurement of cesium and strontium on the irradiation capsule components.

The results of the comparisons between PARFUME predictions and PIE measurements are summarized below:

- Silver

(a) PARFUME predictions and PIE measurements are in reasonably good agreement.

(b) The large distribution in silver release from particle gamma counting can be partially explained by the spatial distribution of temperatures across a compact, as demonstrated by PARFUME calculations.

(c) Low burnup capsules tend to have a higher silver release fraction because they became hotter towards the end of irradiation when silver was readily available for release.

(d) Both PARFUME calculations and PIE data show the trend of higher release fraction at lower burnup, but it is more pronounced in PIE measurements. PARFUME tends to under-predict silver release in the lower burnup capsules and to over-predict it in the higher burnup capsules.

(e) PIE data showed non-negligible retention of silver by the matrix, though retention is not predicted by PARFUME due to the high diffusivity of silver through graphite based on available published data.

- Cesium

(a) The predicted cesium release fractions from particles with failed $\mathrm{SiC}$ are too high by a factor of about 1.3 to 3 , which could mean that the IAEA diffusivity of cesium in the kernel is too high by a factor of 25 to 250 . Calculations performed at lower irradiation temperatures could also possibly explain the observed discrepancies between PARFUME and PIE. An alternative explanation would be the existence of a holdup mechanism in the buffer, PyC or failed SiC layer, which is not taken into account by modeling.

(b) There is an overall over-prediction by PARFUME of cesium release from intact particles by a factor of 2 to 100. Assuming no over-prediction of cesium diffusivity in the kernel, the IAEA diffusivity of cesium in SiC would be too high by 20 to $60 \%$ and $40 \%$ on average.

- Strontium

(a) The release from intact particles is large enough that the contribution from a few particles with failed $\mathrm{SiC}$ cannot be assessed. Furthermore, the PIE data are too scarce to draw any conclusions about the validity of the diffusivity of strontium in UCO.

(b) There is an overall over-prediction by PARFUME of strontium release, suggesting that the IAEA diffusivities of strontium in SiC, UCO or both are too high. The data do not allow a straightforward derivation of more suitable diffusion coefficients for strontium in UCO or SiC.

- For both cesium and strontium, the variation of burnup across compacts cannot account for the discrepancy between PARFUME predictions and PIE measurements. Furthermore, PARFUME should under-predict the average release fraction from all particles in a compact, as measured by PIE, because it does not capture the higher release fractions from the hotter particles. Therefore, PARFUME over-prediction of cesium and strontium release indicates that the IAEA diffusivities of these species are too high at the AGR-1 irradiation temperatures, as detailed above.

The comparison between PARFUME and PIE on silver release shows reasonable agreement. For cesium and strontium, the above conclusions rest upon results obtained on a relatively small number of compacts. Some conclusions have a reasonable level of confidence, but the analysis in terms of correct values of the diffusivities is only tentative. In all cases, there are major factors affecting both the data and the accuracy of PARFUME calculations used in this fractional release assessment, namely:

- Accuracy of the diffusivities

- Accuracy of the predicted compact temperatures

- Spatial distribution of the compact daily temperatures

- Spatial distribution of the sources

- Uncertainty from gamma scanning measurements

- Potential unknown holdup mechanism(s) in the particle 
The existing discrepancies between modeling predictions and experimental data not only point out the need for improvements in existing models but also attest to the good quality of AGR-1 TRISO fuel with respect to fission product release from intact particles. Refining the modeling with spatial burnup and temperature distributions would allow better predictions of the fractional release of the fission products and more accurate comparisons between model predictions and measured results. For silver, comparison with particle gamma counting results poses an additional problem of unknown specific irradiation conditions experienced by the subset of particles, related to their original location within the compacts, which does not seem to be easily solved. Additional PIE data from upcoming AGR experiments would also provide additional data sets for comparison to model predictions. 


\section{ACKNOWLEDGMENTS}

This work was supported by the U.S. Department of Energy, Office of Nuclear Energy, under Department of Energy Idaho Operations Office Contract DE-AC07-05ID14517.

\section{REFERENCES}

[1] G. K. Miller, D. A. Petti, J. T. Maki, D. L. Knudson, "PARFUME Theory and Model Basis Report", INL/EXT-08-14497, Idaho National Laboratory (INL), September 2009.

[2] J. Simonds, "Technical Program Plan for the INL Advanced Reactor Technologies Technology Development Office/Advanced Gas Reactor Fuel Development and Qualification Program", PLN-3636, Rev. 4, Idaho National Laboratory (INL), May 2015.

[3] J. T. Maki, "AGR-1 Irradiation Experiment Test Plan", INL/EXT-05-00593, Rev. 3, Idaho National Laboratory (INL), October 2009.

[4] B. P. Collin, “AGR-1 Irradiation Test Final As-Run Report”, INL/EXT-10-18097, Rev. 3, Idaho National Laboratory (INL), January 2015.

[5] P. A. Demkowicz, "AGR-1 Post-Irradiation Examination Plan", PLN-2828, Rev. 1, Idaho National Laboratory (INL), March 2010.

[6] P. A. Demkowicz, J. D. Hunn, S. A. Ploger, R. N. Morris, C. A. Baldwin, J. M. Harp, P. L. Winston, T. J. Gerczak, I. J. van Rooyen, F .C. Montgomery, C. M. Silva, "Irradiation performance of AGR-1 high temperature reactor fuel", HTR2014-31182, Proceedings of the HTR2014 Conference, Weihai, China, October 27-31, 2014.

[7] J. W. Sterbentz, "JMOCUP As-Run Daily Depletion Calculation for the AGR-1 Experiment in ATR B-10 position", ECAR-958, Rev. 2, Idaho National Laboratory (INL), September 2013.

[8] B. P. Collin, "Comparison of fission product release predictions using PARFUME with results from the AGR-1 irradiation experiment”, INL/EXT-14-31975, Idaho National Laboratory (INL), September 2014.

[9] R. N. Morris, P. A. Demkowicz, J. D. Hunn, C. A. Baldwin, E. L. Reber, "Performance of AGR-1 high temperature reactor fuel during post-irradiation heating tests," HTR2014-31135, Proceedings of the HTR2014 Conference, Weihai, China, October 27-31, 2014.

[10] G. L. Hawkes, “AGR-1 Daily As-run Thermal Analyses”, ECAR-968, Rev. 2, Idaho National Laboratory (INL), January 2012.

[11]J. W. Sterbentz, "JMOCUP As-Run Daily Depletion Calculation for the AGR-1 Experiment in ATR B-10 position", ECAR-958, Rev. 1, Idaho National Laboratory (INL), August 2011.

[12] CEGA Corporation, "NP-MHTGR Material Models of Pyrocarbon and Pyrolytic Silicon Carbide", CEGA002820, Rev. 1, July 1993.

[13] IAEA, "Fuel performance and fission product behaviour in gas cooled reactors", TECDOC-978, November 1997.

[14] K. Verfondern, "TRISO Fuel Performance Modeling and Simulation", Comprehensive Nuclear Materials, Vol. 3 (2012) 755-788.

[15] J. M. Harp, “Analysis of Individual Compact Fission Product Inventory and Burnup for the AGR-1 TRISO Experiment using Gamma Spectrometry", ECAR 1682, Rev. 2, Idaho National Laboratory (INL), June 2013.

[16] J. M. Harp, P. A. Demkowicz, S. A. Ploger, "Post-irradiation examination and fission product inventory analysis of AGR-1 irradiation capsules," HTR2012-3-006, Proceedings the of HTR2012 Conference, Tokyo, Japan, October 28 - November 1, 2012.

[17] J. D. Hunn, C. A. Baldwin, T. J. Gerczak, F. C. Montgomery, R. N. Morris, C. M. Silva, P. A. Demkowicz, J. M. Harp, S. A. Ploger, I. J. van Rooyen, K. E. Wright, "Detection and analysis of particles with breached SiC in AGR-1 fuel compacts," HTR2014-31254, Proceedings of the HTR2014 Conference, Weihai, China, October 27-31, 2014. 


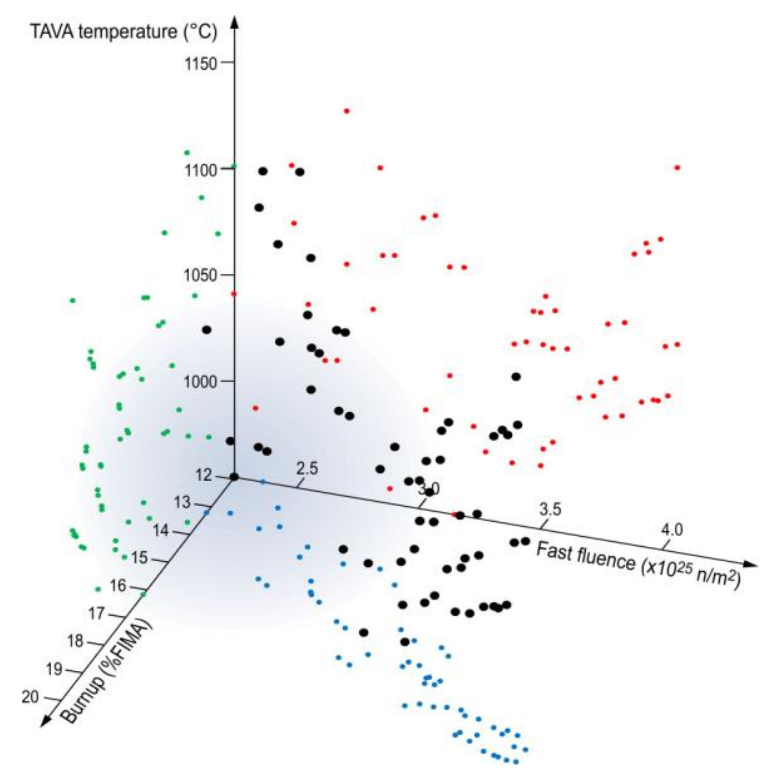

Figure 1. Three-dimensional scatter plots of the irradiation characteristics of the AGR-1 compacts, with projections on two-dimensional plans in blue (burnup vs. fast fluence), green (burnup vs. TAVA temperature), and red (fast fluence vs. TAVA temperature).

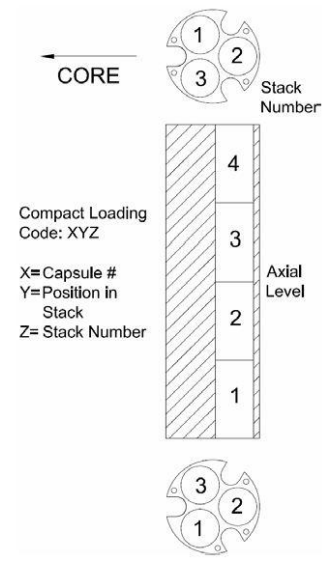

Figure 2. Layout of an AGR-1 capsule. The cross-section view at the top of the figure shows the orientation of the three fuel stacks within the graphite fuel holder and the axial cutaway shows the four axial levels.

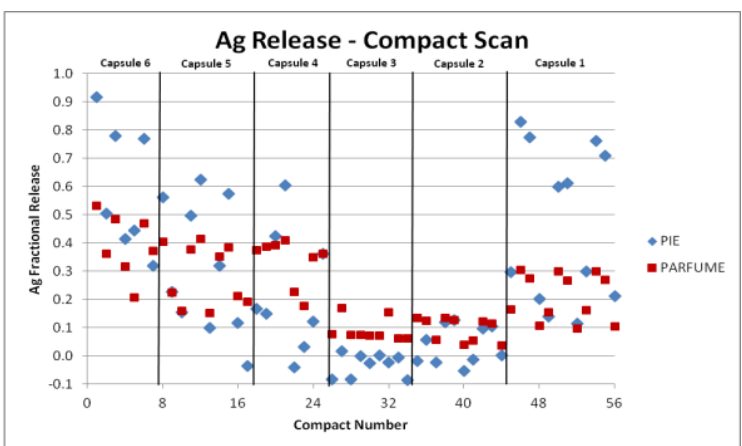

Figure 3. Silver release from compact gamma scanning compared to PARFUME predictions. 


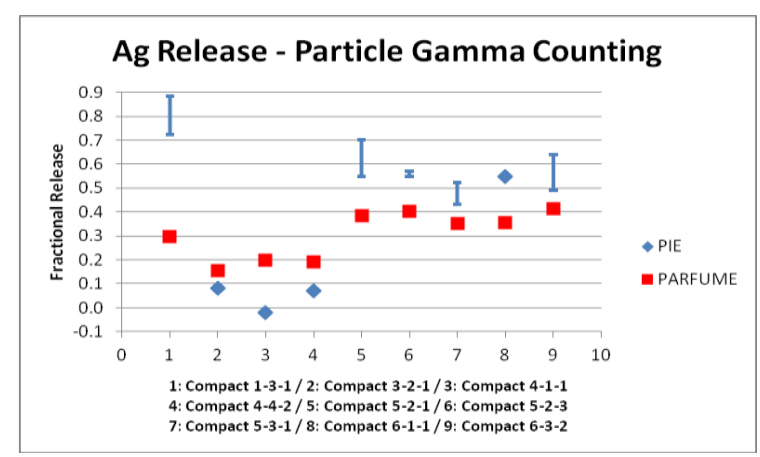

Figure 4. Silver release from particle gamma counting compared to PARFUME predictions.

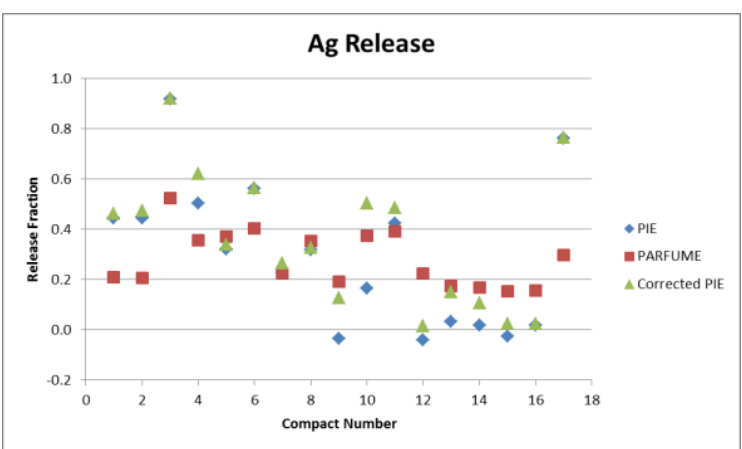

Figure 5. Compact (PIE) and particle (Corrected PIE) release compared to predicted PARFUME release. The numbering of the compacts follows the order of Table 3 (Compact 6-4-3 first on the left).

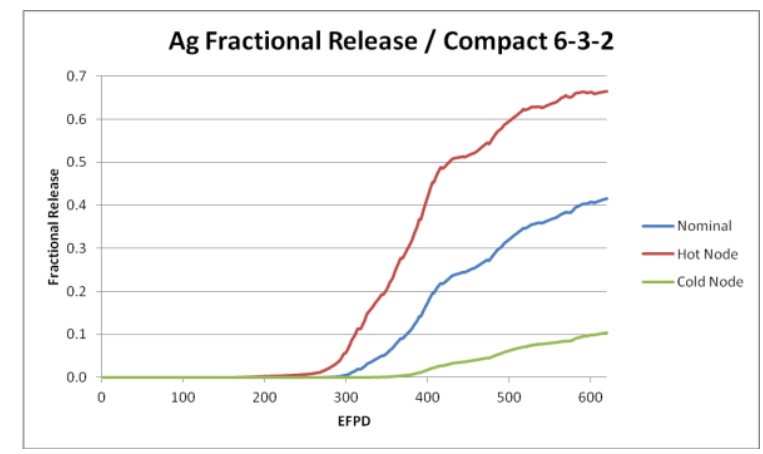

Figure 6. Calculated silver fractional release for the nominal, cold and hot particles in Compact 6-3-2 during the AGR-1 irradiation.

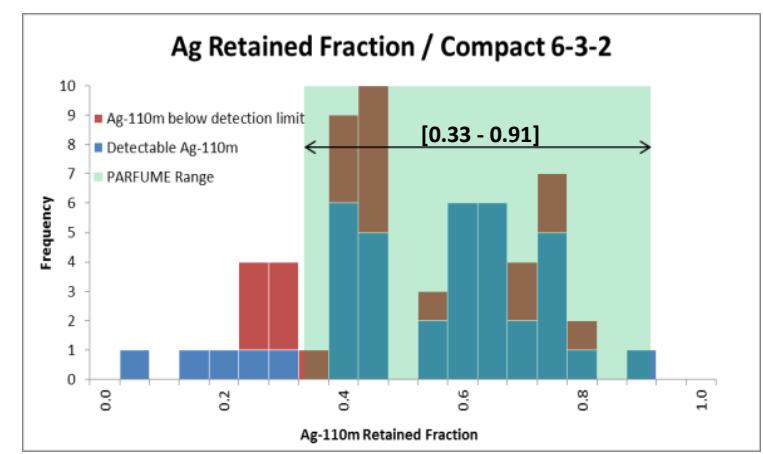

Figure 7. Silver retained fraction of 60 randomly selected particles from Compact 6-3-2 compared to the range of values predicted by PARFUME. 


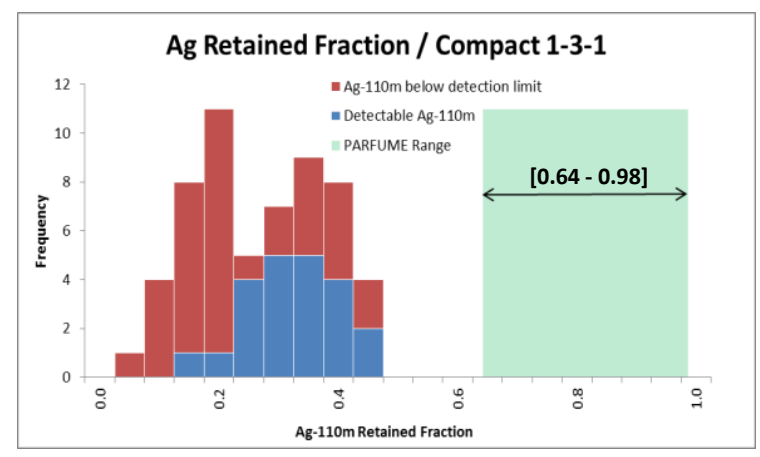

Figure 8. Silver retained fraction of 60 randomly selected particles from Compact 1-3-1 compared to the range of values predicted by PARFUME.

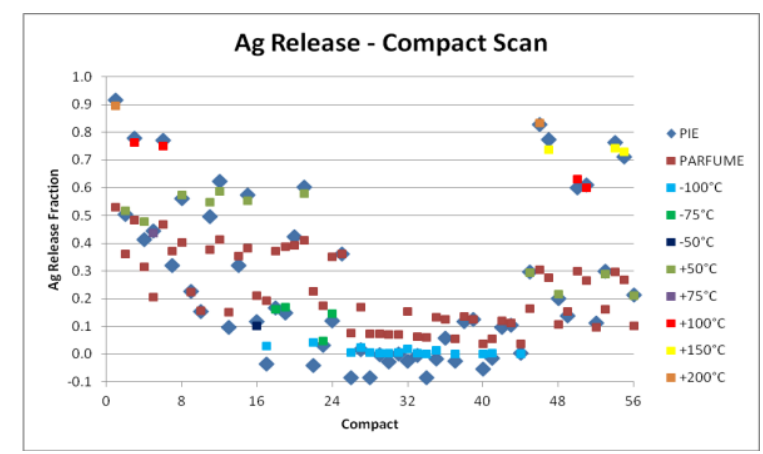

Figure 9. Effect of temperature adjustment on calculated silver.

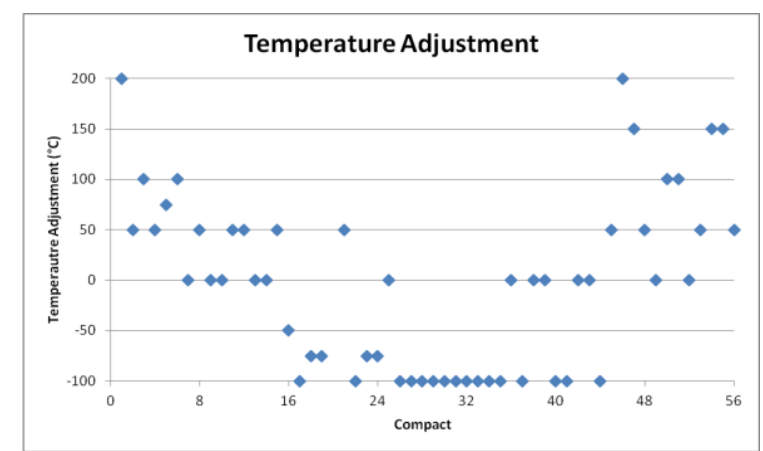

Figure 10. Temperature adjustment required for each compact to have PARFUME match PIE on silver release.

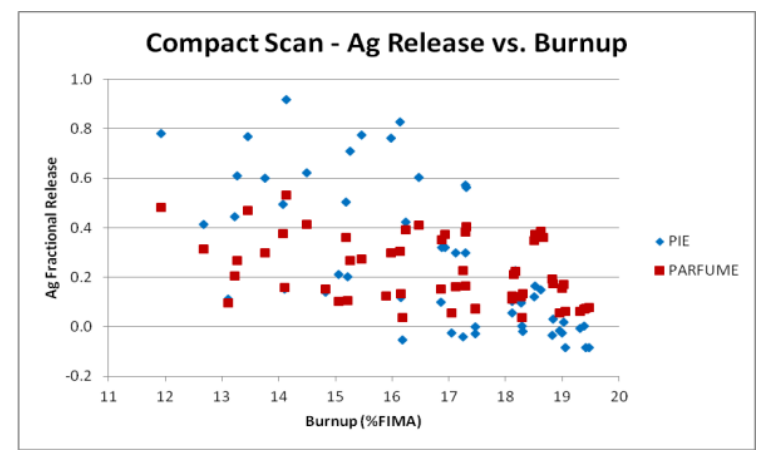

Figure 11. Silver fractional release as a function of burnup. 


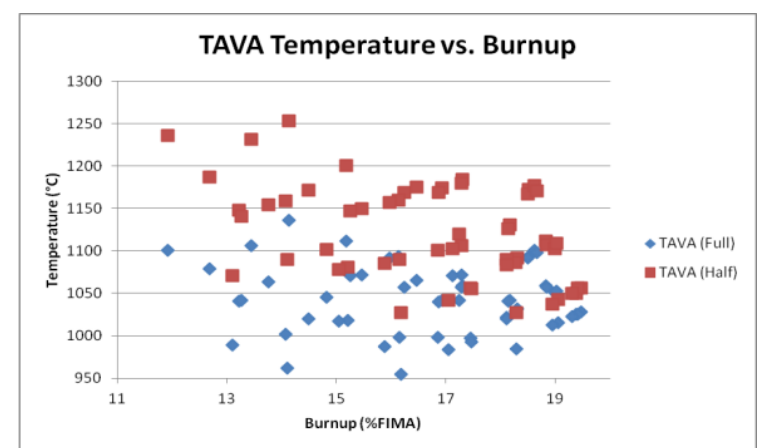

Figure 12. Correlation between burnup and TAVA temperatures calculated for the full irradiation (Full) and for the second half of irradiation (Half).

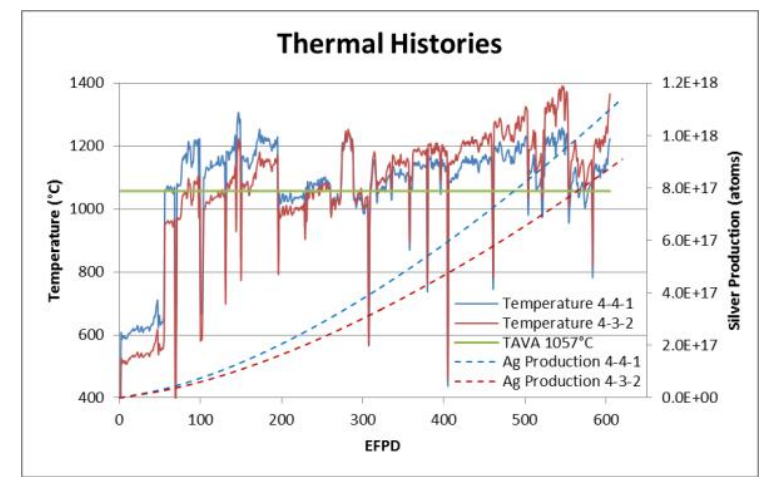

Figure 13. Evolution of daily temperatures and PARFUME-calculated silver production throughout irradiation for Compact 4-4-1 and Compact 4-3-2.

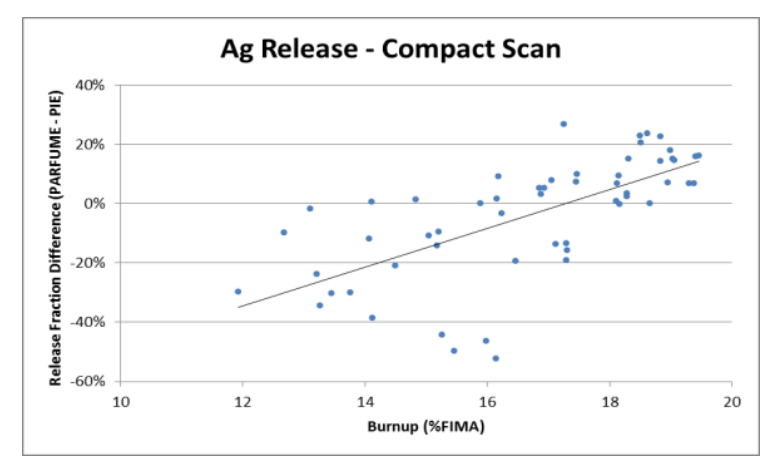

Figure 14. Silver fractional release difference between PARFUME and PIE versus burnup.

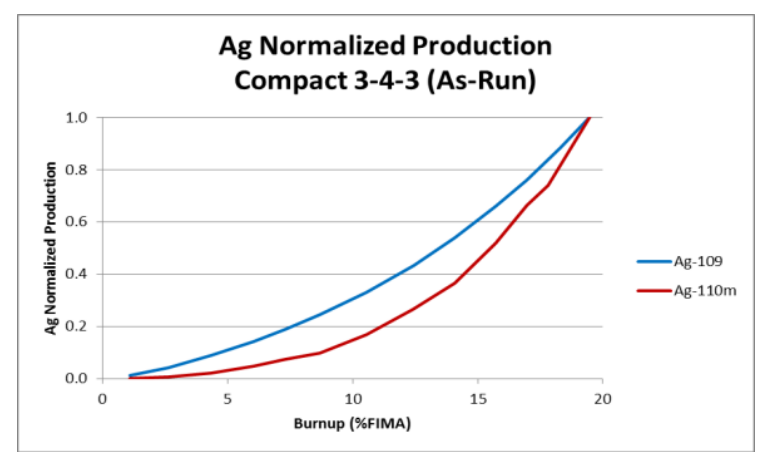

Figure 15. As-run neutronics normalized sources of Ag-109 and Ag-110m as a function of burnup for Compact 34-3. 


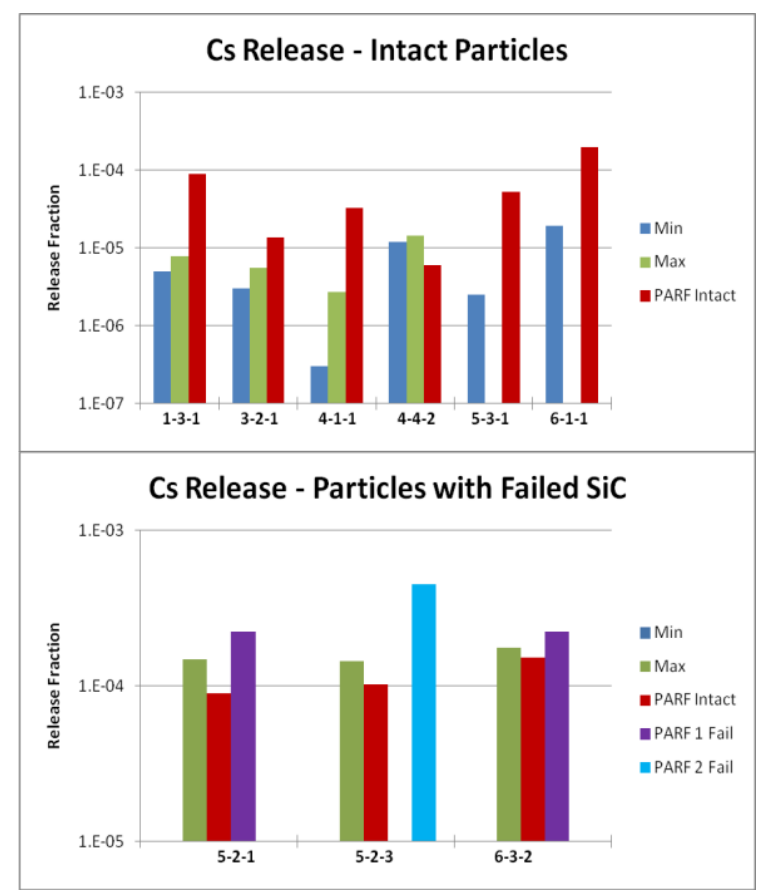

Figure 16: Cesium release from the particles in compacts containing intact particles only (top - a) and containing particles with failed SiC layers (bottom - b). "PARF N Fail" data excludes the contribution from intact particles.

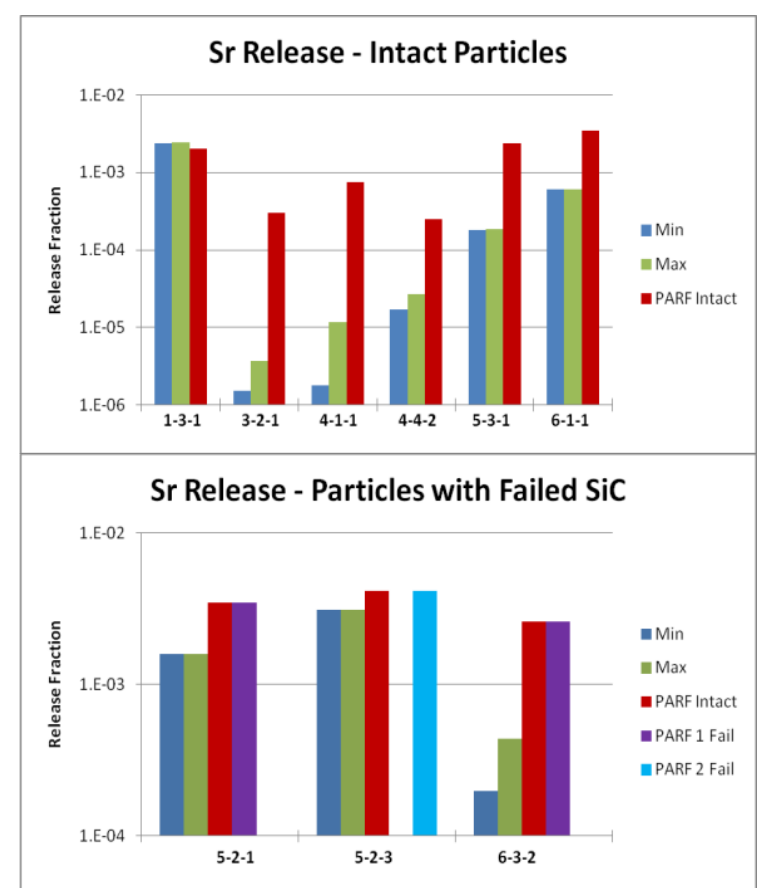

Figure 17: Strontium release from the particles in compacts containing intact particles only (top - a) and containing particles with failed SiC layers (bottom - b). "PARF N Fail" data includes the contribution from intact particles. 


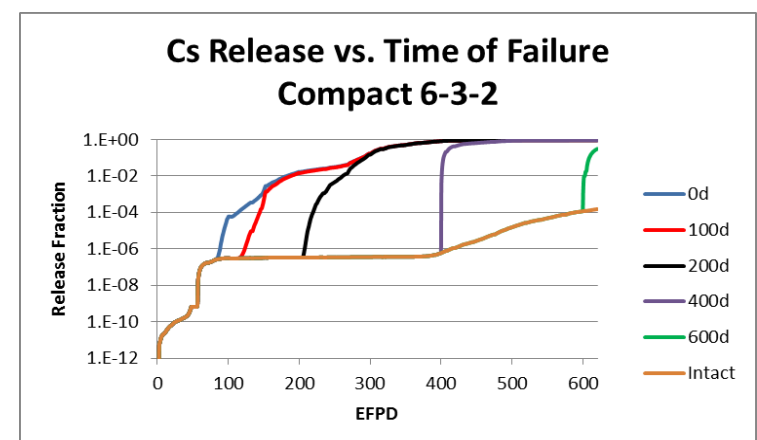

Figure 18: Cesium release fraction from a particle with failed $\mathrm{SiC}$ as a function of time of failure in Compact 6-32. 
Table 1. Compacts used in particle gamma counting and DLBL measurements.

\begin{tabular}{|c|c|c|c|}
\hline Compact & $\begin{array}{c}\text { Burnup } \\
(\mathbf{\%} \text { FIMA })\end{array}$ & $\begin{array}{c}\text { Fast Fluence } \\
\left(\times \mathbf{1 0} \mathbf{2 5}_{\mathbf{n}}^{\mathbf{2}} \mathbf{2}\right. \\
\mathbf{E}>\mathbf{0 . 1 8} \mathbf{M e V})\end{array}$ & TAVA $\left({ }^{\circ} \mathbf{C}\right)$ \\
\hline $\mathbf{6 - 3 - 2}$ & 11.43 & 2.38 & 1070 \\
\hline $\mathbf{6 - 1 - 1}$ & 15.25 & 3.00 & 1111 \\
\hline $\mathbf{5 - 3 - 1}$ & 16.93 & 3.60 & 1040 \\
\hline $\mathbf{5 - 2 - 3}$ & 17.42 & 3.77 & 1059 \\
\hline $\mathbf{5 - 2 - 1}$ & 17.37 & 3.71 & 1057 \\
\hline $\mathbf{4 - 4 - 2}$ & 16.74 & 3.59 & 1072 \\
\hline $\mathbf{4 - 1 - 1}$ & 19.38 & 4.13 & 1051 \\
\hline $\mathbf{3 - 2 - 1}$ & 19.07 & 4.21 & 1092 \\
\hline $\mathbf{1 - 3 - 1}$ & 16.14 & 3.22 & \\
\hline
\end{tabular}

Note: Each compact is uniquely identified in the format X-Y-Z, where $\mathrm{X}$ indicates the capsule, $\mathrm{Y}$ the axial level within the capsule, and $\mathrm{Z}$ the stack (see Figure 2). TAVA stands for time-average volume-average (temperature).

Table 2. Diffusion coefficients used by PARFUME in the AGR-1 irradiation calculations.

\begin{tabular}{|c|c|c|c|c|c|}
\hline \multirow{2}{*}{ Species } & $\begin{array}{c}\mathbf{D}_{\mathbf{0}}\left(\mathbf{m}^{\mathbf{2}} \mathbf{/ s}\right) \\
\mathbf{Q}_{\mathbf{0}}(\mathbf{k J} / \mathbf{m o l})\end{array}$ & $\begin{array}{c}\text { Kernel } \\
\left(\mathbf{U O}_{\mathbf{2}}\right)\end{array}$ & $\mathbf{P y C}$ & $\mathbf{S i C}$ & Matrix graphite \\
\hline \multirow{2}{*}{$\mathbf{A g}$} & $\mathbf{D}_{\mathbf{0}}$ & $6.7 \times 10^{-9}$ & $5.3 \times 10^{-9}$ & $3.6 \times 10^{-9}$ & 1.6 \\
& $\mathbf{Q}_{\mathbf{0}}$ & 165 & 154 & 215 & 258 \\
\hline \multirow{2}{*}{$\mathbf{C s}$} & $\mathbf{D}_{\mathbf{0}}$ & $5.6 \times 10^{-8}$ & $6.3 \times 10^{-8}$ & $5.5 \times 10^{-14}$ & $3.6 \times 10^{-4}$ \\
& $\mathbf{Q}_{\mathbf{0}}$ & 209 & 222 & 125 & 189 \\
\hline \multirow{2}{*}{$\mathbf{S r}$} & $\mathbf{D}_{\mathbf{0}}$ & $2.2 \times 10^{-3}$ & $2.3 \times 10^{-6}$ & $1.2 \times 10^{-9}$ & $1.0 \times 10^{-2}$ \\
& $\mathbf{Q}_{\mathbf{0}}$ & 488 & 197 & 205 & 303 \\
\hline
\end{tabular}

Note: $\mathrm{UO}_{2}$ values are used for the kernel due to lack of data for UCO kernels; the buffer has a set diffusivity of $10^{-8} \mathrm{~m}^{2} / \mathrm{s}$.

Table 3. List of compacts used for assessment of the silver matrix content.

\begin{tabular}{|c|c|}
\hline Capsule & Compacts \\
\hline $\mathbf{6}$ & $6-4-3 / 6-4-1 / 6-2-1 / 6-1-1$ \\
\hline $\mathbf{5}$ & $5-3-3 / 5-2-3 / 5-1-3 / 5-3-1$ \\
\hline $\mathbf{4}$ & $4-4-3 / 4-3-3 / 4-3-2 / 4-1-2 / 4-4-1$ \\
\hline $\mathbf{3}$ & $3-2-3 / 3-3-1 / 3-2-1$ \\
\hline $\mathbf{1}$ & $1-3-1$ \\
\hline
\end{tabular}

Table 4 . Temperature adjustment by capsule.

\begin{tabular}{|c|c|c|c|c|c|c|c|}
\hline & $\mathbf{6}$ & $\mathbf{5}$ & $\mathbf{4}$ & $\mathbf{3}$ & $\mathbf{2}$ & $\mathbf{1}$ & Total \\
\hline $\mathbf{- 1 0 0}^{\circ} \mathbf{C}$ & - & - & 2 & 8 & 6 & - & 16 \\
\hline $\mathbf{- 7 5}^{\circ} \mathbf{C}$ & - & - & 4 & - & - & - & 4 \\
\hline $\mathbf{- 5 0}^{\circ} \mathbf{C}$ & - & 1 & - & - & - & - & 1 \\
\hline $\mathbf{0}^{\circ} \mathbf{C}$ & - & 5 & 2 & - & 5 & 2 & 14 \\
\hline $\mathbf{5 0}^{\circ} \mathbf{C}$ & 2 & 4 & 1 & - & - & 4 & 11 \\
\hline $\mathbf{7 5}^{\circ} \mathbf{C}$ & 1 & - & - & - & - & - & 1 \\
\hline $\mathbf{1 0 0}^{\circ} \mathbf{C}$ & 2 & - & - & - & - & 2 & 4 \\
\hline $\mathbf{1 5 0}^{\circ} \mathbf{C}$ & - & - & - & - & - & 3 & 3 \\
\hline $\mathbf{2 0 0}^{\circ} \mathbf{C}$ & 1 & - & - & - & - & 1 & 2 \\
\hline
\end{tabular}

Table 5. Impact of burnup on Ag calculated release fraction for Compact 4-3-2.

\begin{tabular}{|c|c|c|c|}
\hline & \multicolumn{3}{|c|}{ Burnup } \\
\cline { 2 - 4 } Ag release fraction & $\mathbf{- 2 5 \%}$ & Nominal & $\mathbf{+ 2 5 \%}$ \\
\hline
\end{tabular}

Table 6: PARFUME sets of calculations and use in Cs and $\mathrm{Sr}$ release calculations.

\begin{tabular}{|c|l|c|c|c|c|}
\hline \multirow{2}{*}{$\begin{array}{c}\text { Calculation } \\
\text { set }\end{array}$} & \multirow{2}{*}{ Calculated release } & \multicolumn{2}{|c|}{$\begin{array}{c}\text { Compacts containing intact } \\
\text { particles only }\end{array}$} & $\begin{array}{c}\text { Compacts containing particles } \\
\text { with failed SiC }\end{array}$ \\
\cline { 3 - 6 } & & Cs & Sr & Cs & Sr \\
\hline Set 1 & Release from intact particles & Yes & Yes & No & Yes \\
\hline Set 2 & $\begin{array}{l}\text { Release from particles with } \\
\text { failed IPyC and SiC layers }\end{array}$ & No & No & Yes & Yes \\
\hline
\end{tabular}


Table 7: Impact of burnup on $\mathrm{Cs}$ and $\mathrm{Sr}$ calculated release fractions from an intact particle in Compact 4-1-1 and from a particle with failed $\mathrm{SiC}$ in Compact 6-3-2.

\begin{tabular}{|c|c|c|c|}
\hline \multirow{2}{*}{} & \multicolumn{3}{|c|}{ Burnup } \\
\cline { 2 - 4 } & $\mathbf{- 2 5 \%}$ & Nominal & $\mathbf{+ 2 5 \%}$ \\
\hline Compact 4-1-1 (intact) & $3.2 \times 10^{-5}$ & $3.2 \times 10^{-5}$ & $3.3 \times 10^{-5}$ \\
\hline Cs release fraction & $5.9 \times 10^{-4}$ & $7.6 \times 10^{-4}$ & $9.6 \times 10^{-4}$ \\
\hline Sr release fraction & $92.4 \%$ & $92.5 \%$ & $92.7 \%$ \\
\hline Compact 6-3-2 (failed SiC) & $8.2 \times 10^{-3}$ & $9.6 \times 10^{-3}$ & $1.1 \times 10^{-2}$ \\
\hline Cs release fraction & \multicolumn{3}{|c|}{} \\
\hline Sr release fraction & \multicolumn{3}{|c|}{} \\
\hline
\end{tabular}

Table 8: Impact of temperature on $\mathrm{Cs}$ and $\mathrm{Sr}$ calculated release fractions from an intact particle in Compact 4-1-1 and from a particle with failed $\mathrm{SiC}$ in Compact 6-3-2.

\begin{tabular}{|c|c|c|c|}
\hline \multirow{2}{*}{} & \multicolumn{3}{|c|}{ Calculation Node } \\
\cline { 2 - 4 } Compact 4-1-1 (intact) & Cold & Average \\
\hline Cs release fraction & $1.2 \times 10^{-7}$ & $3.2 \times 10^{-5}$ & $1.2 \times 10^{-3}$ \\
\hline Sr release fraction & $1.9 \times 10^{-7}$ & $7.6 \times 10^{-4}$ & $2.3 \times 10^{-2}$ \\
\hline Compact 6-3-2 (failed SiC) & \multicolumn{3}{|c|}{} \\
\hline Cs release fraction & $66.6 \%$ & $92.5 \%$ & $96.4 \%$ \\
\hline Sr release fraction & $5.2 \times 10^{-4}$ & $9.6 \times 10^{-3}$ & $4.5 \times 10^{-2}$ \\
\hline
\end{tabular}

Note: the uranium contamination fraction in Compact 4-1-1 is $1.3 \times 10^{-7}$. 